\title{
Microclimatic factors influencing refugium suitability for Rhodnius prolixus
}

\author{
THIERRY J.HEGER ${ }^{1}$, PATRICK M. GUERIN ${ }^{1}$ and WER NER \\ E U G T E R ${ }^{2}$ \\ ${ }^{1}$ Institute of Zoology, University of Neuchâtel, Neuchâtel, Switzerland and ${ }^{2}$ Institute of Plant Science, ETH Zürich, \\ Universitätstrasse 2, Zürich, Switzerland
}

\begin{abstract}
Rehydration in the triatomine bug Rhodnius prolixus (Stål) is dependent on the blood meal, and water balance regulation is crucial for survival of starving bugs. In an experimental arena with zones at different climatic conditions, starved $R$. prolixus nymphs prefer a cooler and more humid zone, stopping there more often and for longer periods. This is probably a behavioural adaptation to limit water loss and reduce metabolic rate. In the Venezuelan State of Portuguesa, temperature and humidity were monitored in three kinds of potential refugia during the dry season: (i) in a palm roof; (ii) in a crack of the wall of a house; and (iii) in a palm tree crown. Fluctuations in temperature and saturation deficit are not very different inside and outside the palm roof except during a few hours of the day when the sun is at its zenith. In the crack of the wall, the diurnal temperature range is reduced to $6.5^{\circ} \mathrm{C}$ compared with $12.4{ }^{\circ} \mathrm{C}$ outside, and the saturation deficit varies by only $7.6 \mathrm{hPa}$ compared with $28.6 \mathrm{hPa}$ outside. In the palm tree crown, the daily temperature range is only $4.2^{\circ} \mathrm{C}$ compared with $13.8{ }^{\circ} \mathrm{C}$ outside, and the saturation deficit is permanently $<5 \mathrm{hPa}$. The microclimatic conditions in the palm tree crown would appear to be ideal for starving $R$. prolixus, but this kind of refugium generally harbours low densities of bugs, probably related to a combination of predation, pathogens and lower mean temperature within the crown. Such biotic and abiotic constraints play a lesser role in the less ideal palm roof and wall crack refugia where bugs can proliferate as long as hosts are readily available nearby.
\end{abstract}

Key words. Microclimatic condition, refugium, Rhodnius prolixus, triatomine bug, Venezuela, water balance.

\section{Introduction}

The triatomine bug Rhodnius prolixus Stål, 1859 (Hemiptera: Reduviidae) is an important vector of Trypanosoma cruzi, the causative agent of Chagas disease in Venezuela and other countries in northern Latin America (Schofield, 1994). When host numbers are insufficient, this haematophagous insect, which does not have any other source of water apart from the blood meal and

Correspondence: Dr Patrick Guerin, Institute of Zoology, Case Postale 158, University of Neuchâtel, Rue Emile-Argand 11, 2009 Neuchâtel, Switzerland. Tel.: +4132718 30 66; fax: +41 3271830 01; e-mail: patrick.guerin@unine.ch metabolic water, can support several weeks of starvation (Feliciangeli et al., 1980). During such periods, R. prolixus, similar to other terrestrial arthropods, is particularly vulnerable to water loss, which depends on the prevailing temperature and humidity levels (i.e. saturation deficit). The longevity of starved $R$. prolixus diminishes with increasing temperature at low relative humidity for firstinstar nymphs (Luz et al., 1998). The thermopreferences of many triatomine spp. for cooler refugia increases with the level of starvation (Lazzari, 1991; Canals et al., 1997; Pires et al., 2002; Schilman \& Lazzari, 2004), just as the hygropreference of $T$. brasiliensis for more humid conditions increases with the degree of starvation (Guarneri et al., 2002). This would suggest that triatomine bugs adapt their behaviour according to their physiological state. 
To gain insight into the colonization process of peridomestic and domestic habitats by triatomine bugs, the behavioural preferences of $R$. prolixus are studied in an arena with zones at defined microclimatic conditions. Microclimatic conditions are also recorded in three refugia types in an endemic region with Chagas disease in Venezuela, aiming to obtain a better understanding of the capacity of this species to colonize various habitats.

\section{Materials and methods}

\section{Microclimatic preferences of $R$. prolixus}

Insects. The $R$. prolixus colony is over 20 years old (originating from one at the Swiss Tropical Institute, Basel) and is maintained under a $12: 12 \mathrm{~h}$ LD photoperiod at $28 \pm 2{ }^{\circ} \mathrm{C}$ and $70 \pm 5 \%$ relative humidity $(\mathrm{RH})$ in a climate chamber at Neuchâtel. The bugs are fed on chickens once a month. Experiments were performed with fifth-instar nymphs that were starved for more than 8 weeks after moulting.

Experimental arena. The circular arena was in the upper half of a glass dessicator $(24.6 \mathrm{~cm}$ diameter) and was set up in a walk-in climate chamber maintained at $31.1{ }^{\circ} \mathrm{C}$ and $45 \% \mathrm{RH}$. Three-quarters of the floor of the arena $\left(270^{\circ}\right)$, set $5 \mathrm{~cm}$ below the upper border of the dessicator, comprised a plastic sheet (5 mm thick) and the remaining $\left(90^{\circ}\right)$ was made of aluminium $(1 \mathrm{~cm}$ thick $)$ attached to a Peltier element $\left(35 \mathrm{~cm}^{2}\right)$ to cool this zone of the arena. The hot side of the Peltier element was cooled by pumping water through it from a water bath. In the experiment with uniform temperature and humidity conditions throughout the arena (see below), this pump continued to function to ensure that any vibrations caused by the passage of water were similar between experiments. Both the aluminium and plastic parts of the arena were covered with white paper, which was changed after each experiment using plastic gloves, and the glass borders of the arena were washed with alcohol after each experiment. A $30-\mathrm{cm}$ high black cardboard cylinder surrounded the arena to prevent disturbance from air movements and inequalities in illumination. The arena was rotated $180^{\circ}$ for successive replications.

Computerized video tracking system. Constant nearinfrared illumination $(950 \mathrm{~nm})$ from a lamp (type WFNII, LED 30; Videor Technical E. Hartig GmbH, Germany) located $1.8 \mathrm{~m}$ above the centre of the arena enabled video observations to be made in the dark. Images were acquired every $1 \mathrm{~s}$ using a Philips ToUcam PRO webcam (Philips, The Netherlands) with a built-in infrared-block filter that was replaced by a Kodak 87 infrared-pass filter (Eastman Kodak, Rochester, New York). The webcam was positioned $70 \mathrm{~cm}$ above the centre of the arena. The position of the $R$. prolixus nymph in the arena was calculated from the acquired images using a movingobject tracking software ('CAMTUD'; Perret et al., 2003) running on Linux, providing time-coded tracks with a spatial resolution of $0.5 \mathrm{~mm}$. The $x$ and $y$ coordinates of the limits between the four quarters of the arena were established at the beginning of each experiment.

Arena conditions and behaviour analysis. Temperature and humidity were measured before and after each experiment in the centre of each zone to $0.5 \mathrm{~cm}$ above the floor of the arena using a combined sensor (thermistor probe type FF-U-V10-2, $\pm 0.2{ }^{\circ} \mathrm{C}$, and $\mathrm{RH}$ probe type Vaisala HMP $31 \mathrm{UT}, \pm 3 \%$ ) connected to a Squirrel datalogger (Grant Instruments, U.K.). $R$. prolixus nymphs were observed individually during experiments that each lasted $210 \mathrm{~min}$. In one series of experiments, the climatic conditions were $26.5^{\circ} \mathrm{C}$ and $54 \% \mathrm{RH}$ on the cooled zone and $29.5^{\circ} \mathrm{C}$ and $49 \% \mathrm{RH}$ on the rest of the arena corresponding to saturation deficits of $16 \pm 2 \mathrm{hPa}$ and $21 \pm 2 \mathrm{hPa}$, respectively, as calculated according to Dambach \& Goehlen (1999). In another experimental series, uniform microclimatic conditions of $31.1{ }^{\circ} \mathrm{C}$ and $45 \% \mathrm{RH}$ were maintained throughout the arena, corresponding to a saturation deficit of $25 \pm 2 \mathrm{hPa}$. Each bug was tested individually during the scotophase ( 14 nymphs in the arena with the cool zone and 11 in the arena with uniform microclimatic conditions). The time spent in seconds, the duration of stops longer than $10 \mathrm{~s}$ and the number of stops longer than $10 \mathrm{~s}$ on the different zones of the arena were compared using the data obtained for each bug by the Wilcoxon paired test. A Bonferroni correction was applied to limit the overall error rate arising from multiple comparisons (where $P<0.01$ and $<0.002$ correspond to an experiment error rate of $P<0.05$ and $<0.01$, respectively).

\section{Microclimatic conditions of $R$. prolixus refugia in Venezuela}

Field recordings were conducted in the rural village of El Potrero, Portuguesa State, Venezuela. Some houses of this village have mud walls and palms roofs. The study site is at an elevation of approximately $225 \mathrm{~m}\left(9^{\circ} 10^{\prime} \mathrm{N}\right.$, $\left.69^{\circ} 44^{\prime} \mathrm{W}\right)$ in lowland savanna. The region has a wet season that lasts from May to November and a dry season from December to April with generally very little precipitation (Flecker, 1996). Measurements were made at this site on 1-8 March 2004. Meteorological data of the Ministerio del Ambiente, Guanare (10 km distant from El Potrero) recorded from 1978 to 2003 indicate that March is the warmest month (mean temperature $27{ }^{\circ} \mathrm{C}$, May to November $26^{\circ} \mathrm{C}$ ) and one of the months with the lowest RH (61\% compared with an annual mean RH of $76 \%$ ). Microclimatic conditions were recorded inside three kinds of microhabitats: (i) the palm roof of a chicken-house at $250 \mathrm{~cm}$ from the floor; 
(ii) a crack at $60 \mathrm{~cm}$ from the floor in the mud wall of an inhabited house situated $15 \mathrm{~m}$ from the chicken house; (iii) and in a young palm tree crown (Attalea sp.) at $200 \mathrm{~cm}$ from the ground. The palm tree was situated $4 \mathrm{~km}$ from the chicken house and dwelling. Conditions outside these three refugia were recorded $20 \mathrm{~cm}$ away (i.e. on the palm roof, outside the wall of the house and outside the palm tree crown). Temperature and humidity were recorded every 15 min over a 3-day period using temperature and humidity probes linked to Squirrel dataloggers (see arena conditions above). Saturation deficit (accuracy $\pm 2.5 \mathrm{hPa}$ inside and $\pm 4 \mathrm{hPa}$ outside refugia) and water vapour (accuracy $\pm 3 \mathrm{hPa}$ inside and $\pm 5 \mathrm{hPa}$ outside refugia) were calculated according to Dambach \& Goehlen (1999). The hourly periods of the maximum increase and decrease in temperature and saturation deficit were calculated; values assigned are the means of such hourly differences recorded on three consecutive days.

\section{Results}

Microclimatic preferences of $R$. prolixus

Number of pauses on different zones of the arena. During the 210-min experiment, the number of pauses longer than $10 \mathrm{~s}$ was higher on zone 1 at $26.5^{\circ} \mathrm{C}, 54 \% \mathrm{RH}$ than on zones 2,3 or 4 at $29.5^{\circ} \mathrm{C}, 49 \% \mathrm{RH}$ (Wilcoxon paired test, $P<0.01$; Fig. 1a) with a median number of pauses of 27 , $15.5,8.5$ and 11.5 on zones $1,2,3$ and 4 , respectively. The lowest number of pauses was recorded on zone 3 opposite the cooled more humid zone, but this was not significantly different from the number of pauses on zones 2 or 4 . In the experiment where all four zones of the arena were maintained at the same microclimatic conditions, the difference between the numbers of pauses on zone 1, 2, 3 or 4 was not significantly different $(P>0.01$; Fig. 1 b) with a median number of pauses of $14,16,18$ and 17 , respectively. (a)

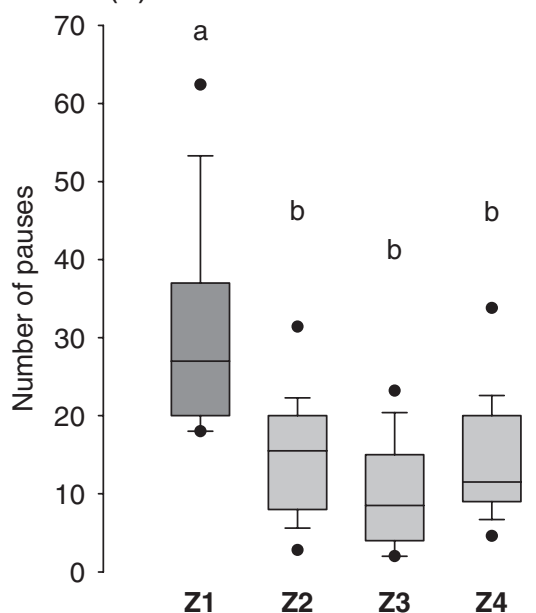

(c)

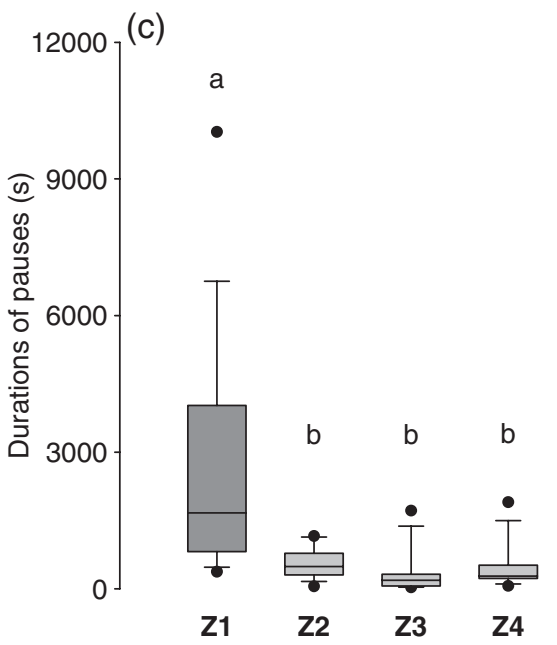

(b)

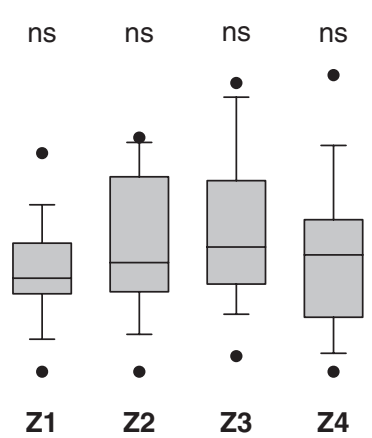

(d)

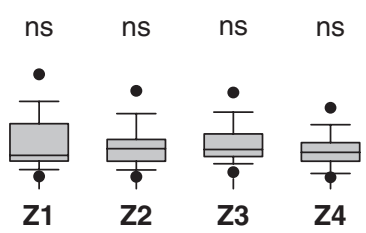

Fig. 1. Box plots of $(a, b)$ the number of pauses and $(c, d)$ the duration of pauses longer than $10 \mathrm{~s}$ made by individual fifth instar Rhodnius prolixus nymphs on the different zones of an arena during the 210-min experiment (see text). In (a) and (c), Z1 represents the zone of the arena at $26.5{ }^{\circ} \mathrm{C}, 54 \% \mathrm{RH}$, and $\mathrm{Z} 2, \mathrm{Z} 3$ and $\mathrm{Z} 4$ represent the other three zones 2,3 and 4 at $29.5{ }^{\circ} \mathrm{C}$ and $49 \% \mathrm{RH}$. Different lettering on boxes indicate significant differences $(P<0.01$; Wilcoxon paired test, $n=14)$. In (b) and (d), Z1 to Z4 represent the duration of pauses on the four zones of the same arena all maintained $31.1^{\circ} \mathrm{C}$ and $45 \% \mathrm{RH}$; ns, no significant difference between zones $(P>0.01$; Wilcoxon paired test, $n=11)$. In the box plots, the lines within a box mark the median, the lower and upper boundary lines of a box indicate the 25th and 75 th percentiles, bars below and above indicate the 10th and 90th percentiles, and 5th and 95th percentiles are shown as circles. 
Duration of pauses on different zones of the arena. The duration of the pauses longer than $10 \mathrm{~s}$ was higher on zone 1 at $26.5{ }^{\circ} \mathrm{C}, 54 \% \mathrm{RH}$ than on zones 2, 3 or 4 at $29.5{ }^{\circ} \mathrm{C}, 49 \%$ RH $(P<0.002$; Fig. 1c) with a median duration of the pauses of 1668.8, 491.1, 189.6 and $278.2 \mathrm{~s}$, respectively. The duration of pauses on zones 2 and 4, neighbouring the zone at the lower temperature, was longer than the duration of the pauses on zone 3 (only the difference between zones 4 and 3 was significant; $P<0.002)$. In the experiment where the arena was maintained with the same climatic conditions throughout, the duration of pauses was not significantly different on zones $1,2,3$ or $4(P>0.01$; Fig. 1d) with a median duration of 513.5, 661.9, 645.1 and $580.8 \mathrm{~s}$, respectively.

Time spent by $R$. proxilus on different zones of the arena. The time spent by $R$. prolixus nymphs was longer in zone 1 at $26.5{ }^{\circ} \mathrm{C}, 54 \% \mathrm{RH}$ than in zones 2 , 3 or 4 at $29.5{ }^{\circ} \mathrm{C}, 49 \% \mathrm{RH}(P<0.002$; Fig. 2a) with a median time spent of 4687.6, 2805.5, 2240.6 and $2705.8 \mathrm{~s}$ on zones 1, 2, 3 and 4, respectively. The time spent on zone 3 , opposite the cooled more humid zone 1, was lower than on zones 2 or 4 bordering 1 (only the difference between zones 3 and 4 was significant; $P<0.002)$. In the experiment where all zones of the arena were maintained at the same condition, the time spent was not significantly different on all four zones $(P>0.01$; Fig. 2 b) with a median time spent of 3113.5 , 2849.8, 3266.2 and $3148.6 \mathrm{~s}$, respectively.

\section{Microclimatic conditions of $R$. prolixus field refugia}

Temperature. The microclimatic conditions inside the three refugia (i.e. the palm roof, the crack in the wall of the house and in the palm tree crown) were buffered compared with the prevailing outside conditions: the daily temperature ranges were lower within the refugia (13.6, 6.5 and $4.2{ }^{\circ} \mathrm{C}$, respectively) than outside $(22.0,12.4$ and $13.8{ }^{\circ} \mathrm{C}$, respectively), and daily maximum and minimum values were delayed (Fig. 3). This buffering was particularly strong inside the crack of the wall and in the palm tree crown. The maximum temperature $\left(35^{\circ} \mathrm{C}\right)$ occurred in the middle of the day in the palm roof whereas the corresponding peak in temperature in the crack of the wall $\left(32^{\circ} \mathrm{C}\right)$ and in the palm tree crown $\left(28^{\circ} \mathrm{C}\right)$ was reached only $3 \mathrm{~h}$ later (Fig. 3$)$.

The hourly maximum increase and decrease of temperature indicates that the rate of change was always higher outside than inside the refugium: for the palm roof, the rate of increase was $6.6^{\circ} \mathrm{C} \mathrm{h}^{-1}$ outside and $5.3{ }^{\circ} \mathrm{C} \mathrm{h}^{-1}$ inside and the rate of decrease was $6.5^{\circ} \mathrm{C} \mathrm{h}^{-1}$ outside and $2.1^{\circ} \mathrm{C} \mathrm{h}^{-1}$ inside; for crack in the wall, the rate of increase was $3.2^{\circ} \mathrm{C} \mathrm{h}^{-1}$ outside and $1.1^{\circ} \mathrm{C} \mathrm{h}^{-1}$ inside and the rate of decrease was $2.2^{\circ} \mathrm{C} \mathrm{h}^{-1}$ outside and $0.6{ }^{\circ} \mathrm{C} \mathrm{h}^{-1}$ inside; for the palm tree crown, the rate of increase was $5.2{ }^{\circ} \mathrm{C} \mathrm{h}^{-1}$ outside and $0.8^{\circ} \mathrm{C} \mathrm{h}^{-1}$ inside and the rate of decrease was $2.7^{\circ} \mathrm{C} \mathrm{h}^{-1}$ outside and $0.8^{\circ} \mathrm{C} \mathrm{h}^{-1}$ inside the crown. The mean temperature was lower in the palm tree crown $\left(25.9^{\circ} \mathrm{C}\right)$ than in the palm roof $\left(27.4{ }^{\circ} \mathrm{C}\right)$ or wall crack $\left(28.3^{\circ} \mathrm{C}\right)$, compared with mean temperatures outside these refugia of $28.1,27.7$ and $26.3{ }^{\circ} \mathrm{C}$, respectively (Fig. 3).

Saturation deficit. The saturation deficit followed the temperature regime in the palm roof and wall crack (Fig. 4a,b), as expected if absolute humidity remains constant when temperature increases, but inside the palm tree crown, the prevailing very low saturation deficit ( $<2 \mathrm{hPa}$ with $\mathrm{RH}$ values over 95\%) remained quite constant despite the daily $4.2{ }^{\circ} \mathrm{C}$ change within the crown (Fig. 4c). As expected from the temperature values estimated above, the hourly maximum increase and decrease of saturation deficit indicates that the rate of change was always higher outside than inside the refugium; for the palm roof, the maximum rate of increase was $18.0 \mathrm{hPa} \mathrm{h}^{-1}$ outside and $11.8 \mathrm{hPa} \mathrm{h}^{-1}$
Fig. 2. (a) Box plots of time spent by individual fifth instar Rhodnius prolixus nymphs on different zones of an arena (see text) during the 210-min experiment where $\mathrm{Z} 1$ is the zone of the arena at $26.5^{\circ} \mathrm{C}, 54 \% \mathrm{RH}$ and $\mathrm{Z} 2, \mathrm{Z} 3$ and $\mathrm{Z} 4$ are the other three zones at $29.5^{\circ} \mathrm{C}, 49 \% \mathrm{RH}$. Different lettering on boxes indicates significant differences between zones $(P<0.002$; Wilcoxon paired test, $n=14$ ). (b) $\mathrm{Z} 1$ to $\mathrm{Z4}$ represent the time spent on four zones of the same arena all maintained at $31.1{ }^{\circ} \mathrm{C}, 45 \%$ RH (ns, no significant difference between zones; $P>0.01$; Wilcoxon paired test, $n=11$ ). The dashed horizontal lines in (a) and (b) indicate the expected value from a uniform distribution. For the box plot presentation, see legend to Fig. 1.

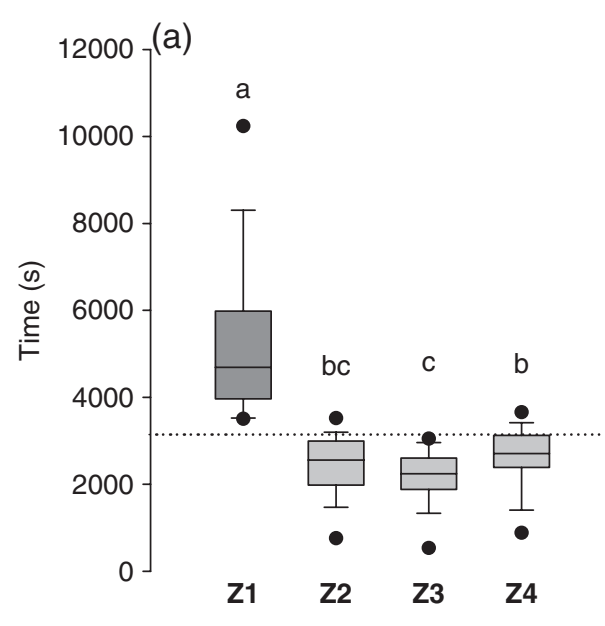

(b)

(C) 2006 The Authors

Journal compilation (C) 2006 The Royal Entomological Society, Physiological Entomology, 31, 248-256 


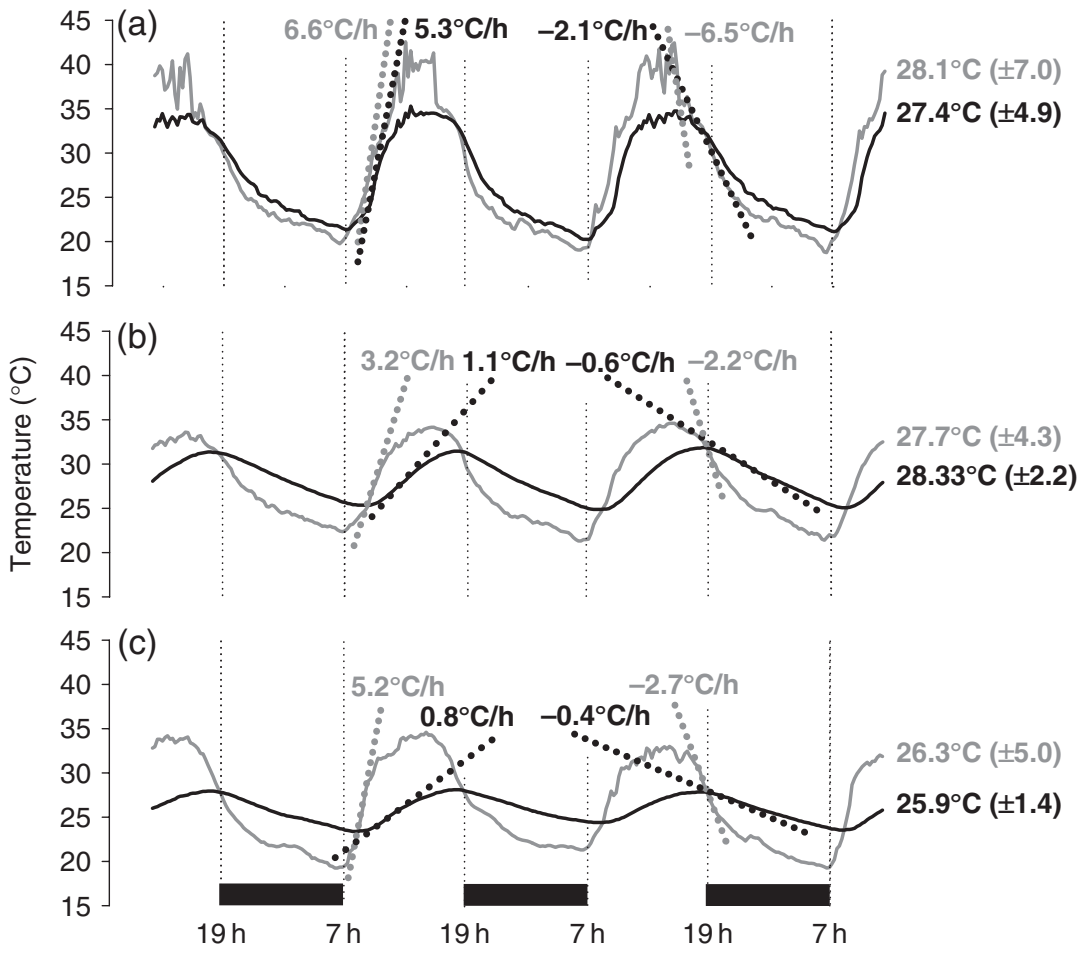

Fig. 3. Temperature values recorded over 3 days in three kinds of Rhodnius prolixus habitats in Portuguesa State, Venezuela during the dry season: (a) palm roof, (b) crack in the wall of a house and (c) palm tree crown. Dotted lines indicate the hours with the steepest increase and decrease in temperature during the hour when the highest changes occurred for the 3-day period. The black line indicates the temperature recorded inside the refugium (see text) and the grey line indicates the temperature recorded just outside the refugium [i.e. on the palm roof in (a), just outside the wall of the house in (b) and within $20 \mathrm{~cm}$ of the palm tree crown in (c)]. Mean \pm SD values for each of the recordings are shown on the right. inside and the maximum rate of decrease was $21.7 \mathrm{hPa} \mathrm{h}^{-1}$ outside and $6.1 \mathrm{hPa} \mathrm{h}^{-1}$ inside. Whereas the peak in saturation deficit was higher outside in the case of the palm roof, the maximum increases and decreases were almost coincident (Fig. 4a). For the wall crack, the maximum rate of increase was $7.5 \mathrm{hPa} \mathrm{h}^{-1}$ outside and $1.4 \mathrm{hPa} \mathrm{h}^{-1}$ inside and the maximum rate of decrease was $6.8 \mathrm{hPa} \mathrm{h}^{-1}$ outside and $1 \mathrm{hPa} \mathrm{h}^{-1}$ inside (Fig. 4b).
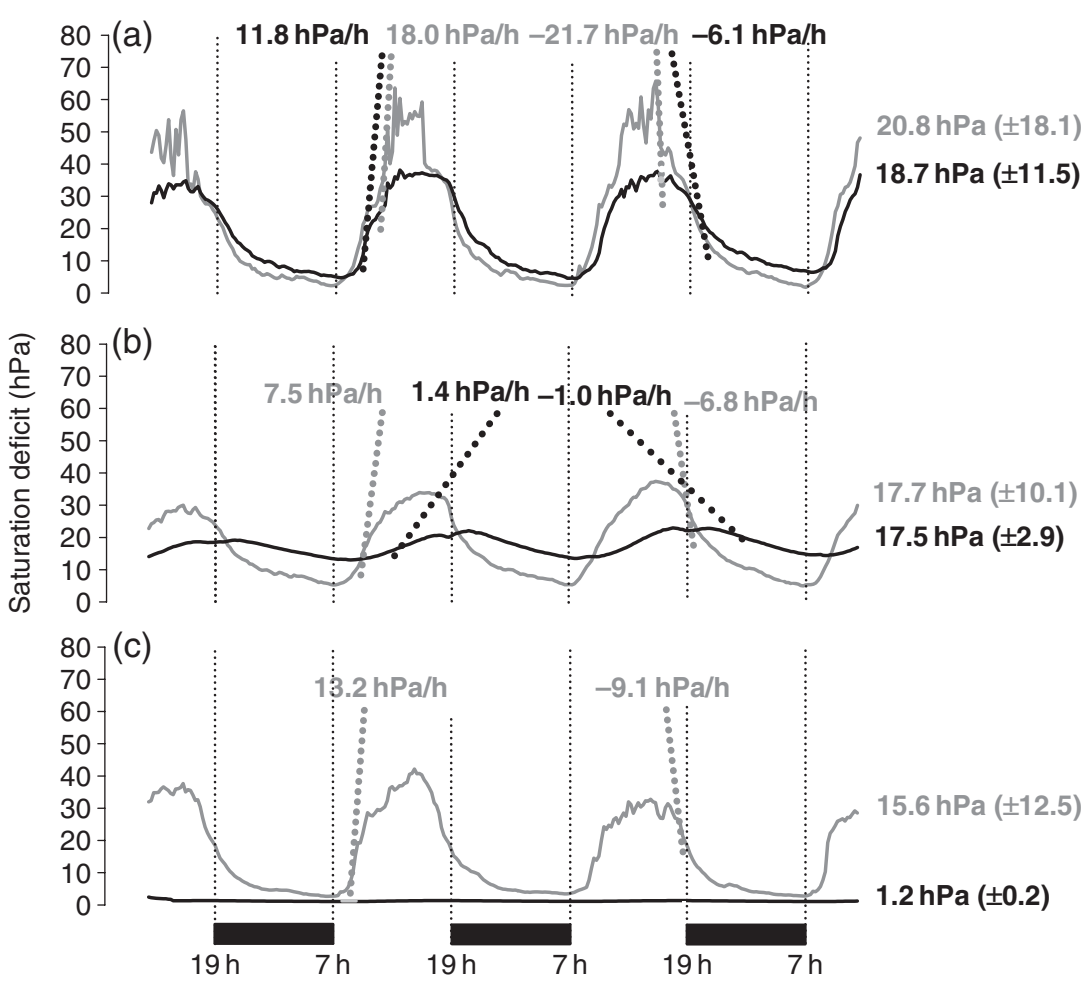

Fig. 4. Saturation deficit values recorded over 3 days in three kinds of Rhodnius prolixus habitats in Portuguesa State, Venezuela during the dry season: (a) palm roof, (b) crack in the wall of a house and (c) palm tree crown. Dotted lines indicate the hours with the steepest increase and decrease in the saturation deficit for the 3-day period. The black line indicates the saturation deficit recorded inside the refugium (see text) and the grey line indicates the saturation deficit recorded just outside the refugium (for further details, see legend to Fig. 3). 
In the wall the maximum rate of change was not only much lower inside the crack but the maximum increases and decreases took place 4 and $5 \mathrm{~h}$ later with respect to the corresponding changes outside. For the palm tree crown, the saturation deficit remained near zero (Fig. 4c). This implies that the palm tree crown responds to increases in temperature by producing more moisture via transpiration, thereby maintaining saturation deficit at a constantly low value.

Water vapour pressure. The water vapour pressure levels within and outside the palm roof were not very different, with the biggest fluctuations $(10 \mathrm{hPa})$ occurring during the course of the day (Fig. 5a). From midnight to mid-day, the water vapour pressure was higher outside than inside the crack in the wall such that water vapour moved into the refugium when vapour pressure was below saturation pressure. Thereafter, the water vapour pressure increased inside the crack to a higher level (maximum difference at $19 \mathrm{~h}$ of $8 \mathrm{hPa}$ ) than outside (Fig. 5b). The biggest differences in water vapour pressure levels were recorded between inside and outside the palm tree crown, with the higher vapour pressure occurring always within the crown (Fig. 5c). The minimum and maximum differences between the water vapour pressure levels inside and outside the palm tree crown occurred at $9 \mathrm{~h}(4 \mathrm{hPa})$ and 17:15h $(20 \mathrm{hPa})$. The morning peak in water vapour pressure outside the palm tree crown results from the evaporation of dew.

\section{Discussion}

Rhodnius prolixus microclimatic preferences in the laboratory arena

The bugs show no preference for a given zone of the experimental arena when the microclimatic conditions are the same throughout. By contrast, the starved nymphs show a clear preference for the cooler and more humid zone of the arena by stopping there more often and for longer periods. Bugs show a slightly higher preference for the zones neighbouring the cooled one by also stopping there more often and for longer periods than on the warmest and driest zone. Schilman \& Lazzari (2004) show that the temperature preference of $R$. prolixus at approximately $25{ }^{\circ} \mathrm{C}$ for males and $25.4{ }^{\circ} \mathrm{C}$ for females varies by only $0.2{ }^{\circ} \mathrm{C}$ throughout the day, and that bugs show an increasing preference for lower temperatures with increasing starvation. Similar observations have been made for other triatomines (Lazzari, 1991; Canals et al., 1997; Pires et al., 2002; Guarneri et al., 2003; Minoli \& Lazzari, 2003). Triatoma brasiliensis shows a preference for lower RH levels immediately after the blood meal but for conditions at higher RH levels 30 days later (Guarneri et al., 2002). These preferences are interpreted as adaptations to maintain a favourable water balance as well as to limit energy loss associated with a higher metabolic rate at higher temperatures. The present observations with $R$. prolixus serve to confirm this and a corresponding behaviour is also demonstrated for other terrestrial arthropods: the
Fig. 5. Water vapour pressure curves recorded over 3 days in three kinds of Rhodnius prolixus habitats in Portuguesa State, Venezuela during the dry season: (a) palm roof, (b) crack in the wall of a house and (c) palm tree. The black line indicates the water vapour pressure recorded inside the refugium (see text) and the grey line indicates the water vapour pressure recorded just outside the refugium (for further details, see legend to Fig. 3). The black arrows indicate water vapour flux from the interior of the refugium to the exterior and grey arrows indicate the reverse.

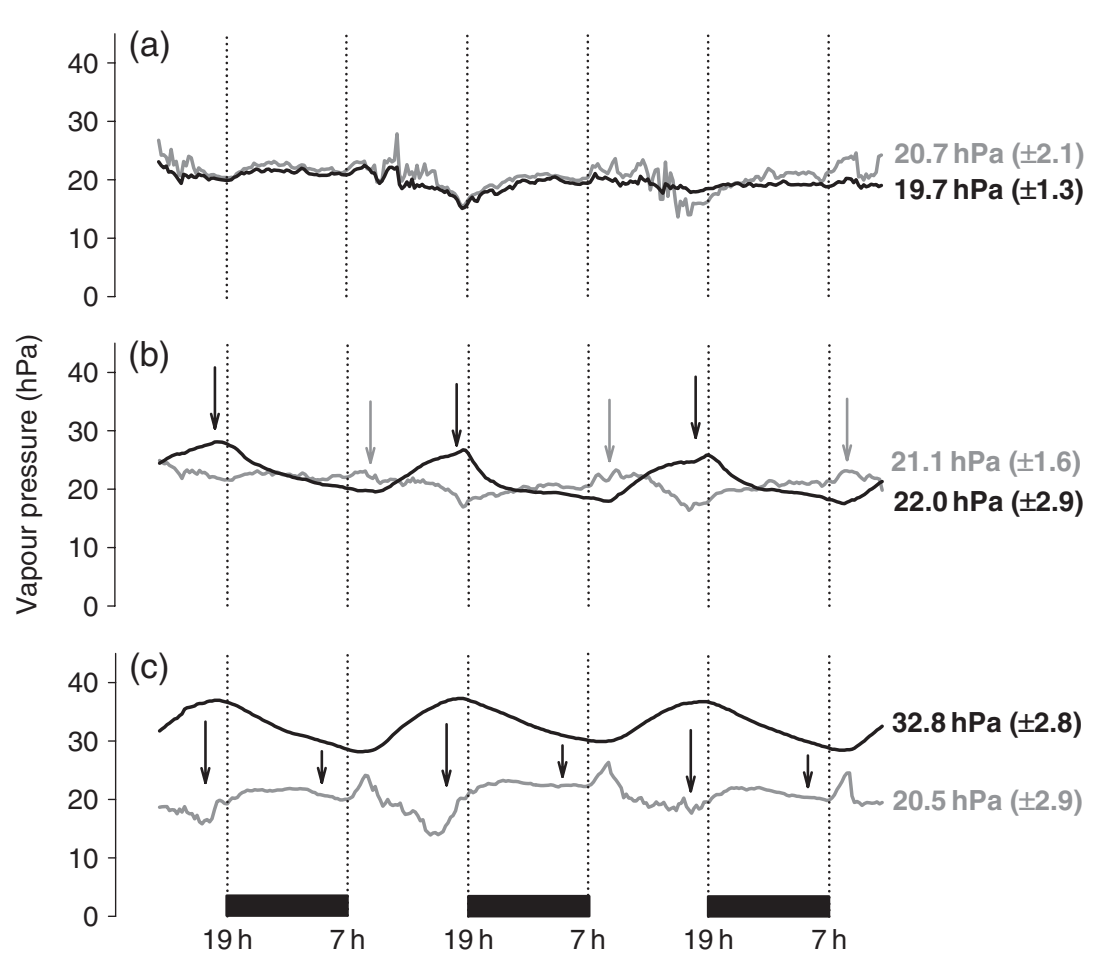


American cockroach, Periplaneta americana, when deprived of food and water, adopts a preference for environments at cooler and more humid conditions (Coenen-Stass, 1976) and the longevity of Blattela germanica deprived of food and drinking water is inversely related to saturation deficit (Dambach \& Goehlen, 1999).

Considering how relative humidity is so closely linked to temperature (Geiger, 1966), the interpretation of experiments bearing on the influence of these environmental factors on insect behaviour is difficult. The mutual interaction between air temperature with air humidity is neglected frequently. Bernard (1974) showed that R. prolixus possesses both antennal thermo- and hygroreceptor cells. It is impossible to know to what extent the lower temperature and/or the $\mathrm{RH}$ level contributes to the preference of $R$. prolixus for the cooler and more humid zone of the arena, but saturation deficit provides a good index of potential transpiration across the cuticule in insects (Edney, 1982). In the arena used in the present study, the lower saturation deficit on the cooler and more moist zone is principally caused by the lower temperature and only secondarily by the RH.

\section{Microclimatic conditions of $R$. prolixus refugia}

Bugs benefit from the refugium in all the habitats studied in that the daily ranges of temperature and saturation deficit are lower within the refugium than outside and their maximum rates of change are also lower. High population densities of $R$. prolixus are commonly observed in palm roofs (Rabinovich et al., 1995). This is the refugium, among those investigated in the present study, that is subjected to the largest oscillations and the highest rates of change in temperature and saturation deficit. Indeed, $R$. prolixus is most sensitive to periods of starvation at fluctuating elevated temperature combined with alternating extremes in humidity levels (Luz et al., 1998). Inside the palm roof refugium, the temperature approaches $35^{\circ} \mathrm{C}$ in the middle of the day. Depending on the length of exposure, a constant temperature of $35^{\circ} \mathrm{C}$ or higher causes irreversible damage to development in $R$. prolixus (Okasha, 1974). However, the development of bugs fed once a week is not impeded at temperatures fluctuating between of 25 and $35^{\circ} \mathrm{C}$ (Luz et al., 1999). The slightly lower saturation deficit inside the palm roof during the day would serve to limit water loss. However, saturation deficit rises exponentially with temperature and, consequently, a small shift in temperature can have a profound influence on cuticular water loss (Appel et al., 1986). By comparison with other haematophagous arthropods such as ticks, where a large part of the cuticule must be produced during the first few days of the blood meal, triatomines have a preformed and extensible cuticule to accomodate the blood meal in minutes. Rhodnius prolixus increases its feeding frequency at high temperatures (Luz et al., 1999), probably to compensate for higher metabolic and water loss rates, and the availability of hosts for regular blood meals in the case of the palm roof refugium is particularly crucial during the dry season. In the present study, potential hosts (principally domestic animals), were present every night near the palm roof and the wall crack refugia where many $R$. prolixus life stages were found.

The water vapour pressure in the crack of the wall increases throughout the day, the opposite to that occuring outside the refugium. Consequently, water vapour leaves the crack in the wall from the middle of the day because water vapour will move from a zone at a higher pressure to one at a lower pressure (Edney, 1977). In this manner, heat can be eliminated from the crack of the wall from the middle of the day by the prevailing water vapour flux. Air movement outside the refugium needs to be taken into account to accurately quantify this flux of water vapour and heat, a factor that was not measured in this study. The vapour that escapes from the crack is probably compensated by evaporation of water (using sensible heat) that had previously condensed there. This is most likely the principal means of maintaining a lower saturation deficit and cooler temperature within such refugia. The water vapour pressure remains very high inside the palm tree crown (minimum reached at the beginning of the day of $28.8 \mathrm{hPa}$ ) as a consequence of the very high relative humidity. This high constant water vapour pressure implies a constant water vapour loss to the outside of the crown. However, it is probably transpiration of the palm tree that serves to dampen the effect of high daily temperature outside this refugium.

During the scotophase, triatomines leave their refugia to search, among other things, for a blood meal (Zeledón \& Rabinovich, 1981). Triatoma infestans is able to synchronize its circadian clock with environmental temperature cycles (Lazzari, 1992). The present study demonstrates that starving $R$. prolixus show a preference for zones of lower temperature and higher humidity. When such conditions occur regularly outside the crack in the wall at night, they probably reinforce the existing tendency of bugs to emerge from peridomestic and domestic refugia. However, triatomines returning to such refugia before daybreak encounter the opposite (i.e. higher temperatures and saturation deficits). In this case, it should be assumed that the light/dark cycle plays a primary role in influencing refugium exit and entry, confirming the predominant role of light in the synchronization of triatomine activity (Lazzari, 1992). The net effect of this behavioural pattern (i.e the return into the refugia before daybreak) is a reduction in water loss during the hottest time of the day. Aggregations of insects within refugia can contribute to reducing water loss in another way as the saturation deficit increases during the course of the day. Groups of the cockroach Blattella germanica show a greater tendency to aggregate under lower humidities than under higher humidities, and it is suggested that the net loss of water from each individual will be limited (Dambach \& Goehlen, 1999). This scenario is probably equally relevant for $R$. prolixus. Furthermore, triatomines can themselves influence the RH of the refugium by the way that they loose water: groups of 28 freshly 
fed $R$. prolixus adults caused an increase of over $10 \%$ in two $500-\mathrm{cm}^{3}$ glass jars over the 12 days after a blood meal (Heger, 2004). Even if $R$. prolixus habitually excretes a large part of its blood meal shortly before regaining the refugium (Wigglesworth, 1931), replete bugs can still contribute to overall refugium humidity.

The refugia that can be exploited by $R$. prolixus in different types of habitats each have their own advantages and constraints. With its less fluctuating temperature regime and almost no saturation deficit, microclimatic conditions inside the palm tree crown would initially appear to provide the ideal microclimatic conditions for starving $R$. prolixus. However, the lower mean temperature inside the palm tree crown compared with the other refugia studied here imposes a longer development time for each $R$. prolixus life stage. In addition, the near saturation of the air within this refugium exposes the bugs to a higher risk of infection by pathogens (Romaña \& Fargues, 1992; Luz, 1994). There may also be an increased rate of predation on triatomines within the palm tree crown where the animals that constitute the main blood source for the bugs are only occasional visitors (Zeledón \& Rabinovich, 1981). Domestic and peridomestic refugia such as cracks in walls of houses and the refugium in the palm roof partly relieve the bugs of such abiotic and biotic constraints, permitting them to proliferate as long as hosts are readily available nearby.

\section{Acknowledgements}

We thank Dr Jean-Luc Perret for help with the videotracking system; Professors Elis Aldana of the Herman Lent Laboratory and Luisana Avilan, Department of Biology, University of Los Andes, Mérida, Venezuela for providing facilities; the Figueredo Family of El Potrero, Portuguesa State, Venezuela for their hospitality during the field study. At the University of Neuchâtel, Fernando Otálora-Luna helped with rearing of $R$. prolixus and provided criticism of the manuscript, Dr Jacqueline Moret, Institute of Mathematics advised on statistical analysis of the data and Professor P.-A. Diehl made useful comments on the manuscript. The field research of T.H. was supported by the Wüthrich and Mathey-Dupraz Foundations, University of Neuchâtel.

\section{References}

Appel, A.G., Reierson, D.A. \& Rust. M.K. (1986) Cuticular water loss in the smokybrown cockroach, Periplaneta fuliginosa. Journal of Insect Physiology, 32, 623-628.

Bernard, J. (1974) Etude électrophysiologique de récepteurs impliqués dans l'orientation vers l'hôte et dans l'acte hématophage chez un hémiptère: Triatoma infestans. Thèse, Université Rennes, France.

Canals, M., Rigoberto, S., Valderas, J. et al. (1997) Preliminary studies on temperature selection and activity cycles of Triatoma infestans and T. spinolai (Heteroptera: Reduviidae), Chilean vectors of Chagas' disease. Journal of Medical Entomology, 34, $11-17$.

Coenen-Stass, D. (1976) Vorzugstemperatur und Vorzugsluftfeuchigkeit der beiden Schabenarten Periplaneta americana und Blaberus trapezoideus (Insecta: Blattaria). Entomologia Experimentalis et Applicata, 20, 143-153.

Dambach, M. \& Goehlen, B. (1999) Aggregation density and longevity correlate with humidity in first-instar nymphs of the cockroach (Blattella germanica L., Dictyoptera). Journal of Insect Physiology, 45, 423-429.

Edney, E.B. (1977) Water Balance in Land Arthropods. Springer, Germany.

Edney, E.B. (1982) The truth about saturation deficiency-an historical perspective. Journal of Experimental Zoology, 222, 205-214.

Feliciangeli, M.D., Rabinovich, J. \& Fernandez, E. (1980) Resistencia al ayuno en triatominos (Hemiptera, Reduviidae) venezolanos. Revista Do Instituto de Medicina Tropical de São Paulo, 22, 53-61.

Flecker, A.S. (1996) Ecosystem engineering by a dominant detritivore in a diverse tropical ecosystem. Ecology, 77, $1845-1854$.

Geiger, R. (1966) The Climate Near the Ground, 2nd edn. Harvard University Press, Cambridge, Massachusetts.

Guarneri, A.A., Lazzari, C.R., Diotaiuti, L. \& Lorenzo, M.G. (2002) The effect of relative humidity on the behaviour and development of Triatoma brasiliensis. Physiological Entomology, 27, 142-147.

Guarneri, A.A., Lazzari, C.R., Xavier, A.P.P. et al. (2003) The effect of temperature on the behaviour and development of Triatoma brasiliensis. Physiological Entomology, 28, 185-191.

Heger, T.J. (2004) Behavioural adaptations and importance of microclimatic conditions for the maintenance of their water balance in two species of Triatominae (Hemiptera: Reduviidae), Rhodnius prolixus and Triatoma nigromaculata. Diploma work, Université de Neuchâtel, Switzerland.

Lazzari, C.R. (1991) Temperature preference in Triatoma infestans (Hemiptera: Reduviidae). Bulletin of Entomological Research, 81, 273-276.

Lazzari, C.R. (1992) Circadian organization of locomotion activity in the haematophagous bug Triatoma infestans. Journal of Insect Physiology, 38, 895-903.

Luz, C. (1994) Biologische Bekämpfung der Überträger der Chagaskrankheit (Triatominae). Einfluss von Temperatur und Luftfeuchtigkeit auf die larvale Entwicklung von Rhodnius prolixus sowie die Infektion mit Beauveria bassiana (Deuteromycetes) und Sporulation des Pilzes auf den Kadavern. PhD Thesis, Universität Tübingen, Germany.

Luz, C., Fargues, J. \& Grunewald, J. (1998) Effect of fluctuating temperature and humidity on the longevity of starved Rhodnius prolixus (Hem., Triatominae). Journal of Applied Entomology, 122, 219-222.

Luz, C., Fargues, J. \& Grunewald, J. (1999) Development of Rhodnius prolixus (Hemiptera: Reduviidae) under constant and cyclic conditions of temperature and humidity. Memorias Do Instituto Oswaldo Cruz, 94, 403-409.

Minoli, S.A. \& Lazzari, C.R. (2003) Chronobiological basis of thermopreference in the heamatophagous bug Triatoma infestans. Journal of Insect Physiology, 49, 927-932.

Okasha, A.Y.K. (1974) Effects of high temperature in Rhodnius prolixus (Stål). Nature, 204, 1221-1222. 
Perret, J.-L., Guerin, P.M., Diehl, P.A. et al. (2003) Darkness induces mobility, and saturation deficit limits questing duration, in the tick Ixodes ricinus. Journal of Experimental Biology, 206, $1809-1815$.

Pires, H.H.R., Lazzari, C.R., Schilman, P.E. et al. (2002) Dynamics of thermopreference in the Chagas vector Panstrongylus megistus (Hemiptera: Reduviidae). Journal of Medical Entomology, 39, 716-719.

Rabinovich, J.E., Gürtler, R.E., Leal, J. \& Piñero, D.F. (1995) Density estimates of the domestic vector of Chagas disease, Rhodnius prolixus Stål (Hemiptera, Reduviidae), in rural houses in Venezuela. Bulletin of the World Health Organization, 73, 347-357.

Romaña, C.A. \& Fargues, J. (1992) Relative susceptibility of different stages of Rhodnius prolixus to the entomopathogenic hyphomycetes Beauveria bassiana. Memorias Do Instituto Oswaldo Cruz, 87, 363-368.
Schilman, P.E. \& Lazzari, C.R. (2004) Temperature preference in Rhodnius prolixus, effects and possible consequences. Acta Tropica, 90, 115-122.

Schofield, C.J. (1994) Triatominae - Biology and Control. Eurocommunica Publications, U.K.

Wigglesworth, V.B. (1931) The physiology of excretion in a bloodsucking insect, Rhodnius prolixus (Hemiptera, Reduviidae). I. Composition of the urine. Journal of Experimental Biology, 8 , 411-427.

Zeledón, R. \& Rabinovich, J.E. (1981) Chagas' disease: an ecological appraisal with special emphasis on its insect vectors. Annual Review of Entomology, 26, 101-133.

Accepted 11 January 2006

First published online 13 April 2006 